\title{
ARTICLE
}

\section{Application of neutron shield concrete to neutron scattering instrument TAIKAN in J-PARC}

\author{
Koichi Okuno $^{\mathrm{a}^{*}}$, Masayoshi Kawai ${ }^{\mathrm{b}}$, Hitoshi Yamada ${ }^{\mathrm{a}}$, Takenao Shinohara ${ }^{\mathrm{c}}$, \\ Shin-ichi Takata ${ }^{c}$, Jun-ichi Suzuki ${ }^{d}$, Kentaro Suzuyac and Kazuya Aizawa ${ }^{c}$ \\ ${ }^{a}$ Hazama Technical Research Institute, 515-1 Karima, Tsukuba, Ibaraki, 305-0822, Japan; ${ }^{b}$ High Energy Accelerator Research \\ Organization (KEK), 1-1 Oho, Tsukuba, Ibaraki, 305-0801, Japan; ' Japan Atomic Energy Agency (JAEA), 2-4 Shirakata, \\ Tokai-mura, Naka-gun, Ibaraki, 319-1195, Japan; ${ }^{d}$ Comprehensive Research Organization for Science and Society (CROSS), \\ 162-1 Shirakata Tokai-mura, Naka-gun, Ibaraki, 319-1106, Japan
}

\begin{abstract}
The main neutron shield for the neutron beam line and neutron spectrometer at J-PARC consists of multilayers of iron and ordinary concrete or boric acid resin and ordinary concrete. However, the available space inside the shield will become limited since a multilayer shield must have sufficient thickness to guarantee radiation safety outside of the shield. Recently, a neutron shield concrete was developed and applied to the shield for the TAIKAN neutron scattering instrument at J-PARC. Neutron transport calculations revealed that the shield's thickness could be reduced to about $70 \%$ of that of the original design, which used ordinary concrete. The resulting slim neutron shield structure could leave more space in the interior shielded areas.
\end{abstract}

Keywords: neutrons; J-PARC; concrete; PHITS; neutron scattering

\section{Introduction}

The main neutron shield for the neutron beam line and neutron spectrometer at the Japan Proton Accelerator Research Complex (J-PARC) consists of multilayers of iron and ordinary concrete (OC) or boric acid resin (BAR) and OC. BAR is a mixture of boric acid, polyethylene beads, and epoxy adhesives. However, the available interior space will become limited since a multilayer shield must have sufficient thickness to guarantee radiation safety outside of the shield. The construction cost is expected to be higher for such a shield because two shielding materials are needed. In addition, the construction work is complicated.

A neutron shield concrete (NSC) was recently developed to realize compact shields for various neutron facilities ${ }^{1)}$. If the concrete is applied to various neutron scattering instruments, indoor space of the instruments can expand and also reduction of construction cost is expected. Therefore, the concrete is applied to the shield for the TAIKAN neutron scattering instrument at J-PARC. In the present work, shielding calculation for the concrete and the TAIKAN were carried out.

TAIKAN is installed on Beam Line No. 15 (BL15) at the J-PARC Material and Life Science Experimental Facility (MLF). It is a small-angle neutron scattering instrument that analyzes the micro- and nano-structures

*Corresponding author. Email: okuno.koichi@ad-hzm.co.jp of materials (e.g., polymers and alloys). TAIKAN uses neutrons with energies ranging from $10^{-3} \mathrm{eV}$ to $0.3 \mathrm{eV}$.

\section{Neutron shield concrete}

The NSC is made from colemanite and peridotite rocks used together as the aggregate with ordinary Portland cement, forming concrete. Colemanite is a natural mineral that is rich in boron in the form of $\mathrm{B}_{2} \mathrm{O}_{3}$. Peridotite is a natural mineral that is rich in hydrogen atoms in the form of $\mathrm{H}_{2} \mathrm{O}$.

Colemanite can be used for up to around $15 \mathrm{wt} \%$ of the concrete composition to improve the shielding performance and the production of concrete.

NSC has the same density as OC. Therefore, its shielding performance against photons is the same as that of OC. The NSC includes boron in the form of $\mathrm{B}_{2} \mathrm{O}_{3}$, which has a large capture cross-section for thermal neutrons, and abundant hydrogen in the form of $\mathrm{H}_{2} \mathrm{O}$, which slows down higher-energy neutrons of around 2 $\mathrm{MeV}$ by elastic scattering. It also includes more iron in the form of $\mathrm{Fe}_{2} \mathrm{O}_{3}$ than $\mathrm{OC}$, so it slows down higher-energy neutrons by inelastic scattering. These effects give it its shielding characteristics. The density and elemental contents of NSC and OC are shown in Table 1.

The shielding performance for the NSC was estimated for a ${ }^{252} \mathrm{Cf}$ neutron source that has fission 
spectrum of average energy of $2.3 \mathrm{MeV}$, but for other energies, it was not estimated. Therefore, the shielding properties for thermal neutrons, $100 \mathrm{keV}$ neutrons, and DD neutrons $(2.45 \mathrm{MeV})$ that produced fusion device were calculated using MCNP5 $5^{2}$. The calculation model is shown in Figure 1. A surface source and a surface crossing estimator were used in this calculation.

Figure 2 shows the total amount of the calculated neutron and gamma-ray doses for each neutron source. The neutron energy range for thermal neutrons was set to less than the cadmium cutoff energy in this calculation.

Table 1. Results of density and elemental analysis.

\begin{tabular}{ccccc}
\hline \multicolumn{5}{c}{ Neutron shield concrete $(w t \%)$} \\
\hline $\mathrm{SiO}_{2}$ & $\mathrm{H}_{2} \mathrm{O}$ & $\mathrm{MgO}$ & $\mathrm{MnO}$ & $\mathrm{Al}_{2} \mathrm{O}_{3}$ \\
\hline 33.1 & 14.8 & 29.1 & 0.09 & 1.54 \\
\hline $\mathrm{CaO}$ & $\mathrm{SO}_{3}$ & $\mathrm{Cl}$ & $\mathrm{Cs}$ & $\mathrm{Na}_{2} \mathrm{O}$ \\
\hline 11 & 0.38 & 0.016 & $<0.01$ & 0.05 \\
\hline $\mathrm{TiO}_{2}$ & $\mathrm{~B}_{2} \mathrm{O}_{3}$ & $\mathrm{P}_{2} \mathrm{O}_{5}$ & $\mathrm{Eu}$ & $\mathrm{CoO}$ \\
\hline 0.07 & 2.61 & 0.11 & $<0.01$ & $<0.01$ \\
\hline $\mathrm{Fe}_{2} \mathrm{O}_{3}$ & $\mathrm{~K}_{2} \mathrm{O}$ & $\mathrm{Ig}-$ loss & \multicolumn{2}{c}{ Density } \\
\hline 6.23 & 0.06 & 13.6 & \multicolumn{2}{c}{$2.2 \mathrm{~g} / \mathrm{cm}^{3}$} \\
\hline
\end{tabular}

\begin{tabular}{ccccc}
\multicolumn{5}{c}{ Ordinary concrete $(w t \%)$} \\
\hline $\mathrm{SiO}_{2}$ & $\mathrm{H}_{2} \mathrm{O}$ & $\mathrm{MgO}$ & $\mathrm{MnO}$ & $\mathrm{Al}_{2} \mathrm{O}_{3}$ \\
\hline 57.7 & 6.04 & 1.31 & 0.08 & 10.5 \\
\hline $\mathrm{CaO}$ & $\mathrm{Cs}$ & $\mathrm{Na}_{2} \mathrm{O}$ & $\mathrm{K}_{2} \mathrm{O}$ & $\mathrm{TiO}_{2}$ \\
\hline 14.5 & $<0.01$ & 2.29 & 0.86 & 0.39 \\
\hline $\mathrm{Fe}_{2} \mathrm{O}_{3}$ & $\mathrm{Eu}$ & $\mathrm{Co}$ & \multicolumn{2}{c}{ Density } \\
\hline 3.47 & $<0.01$ & $<0.01$ & \multicolumn{2}{c}{$2.2 \mathrm{~g} / \mathrm{cm}^{3}$} \\
\hline
\end{tabular}

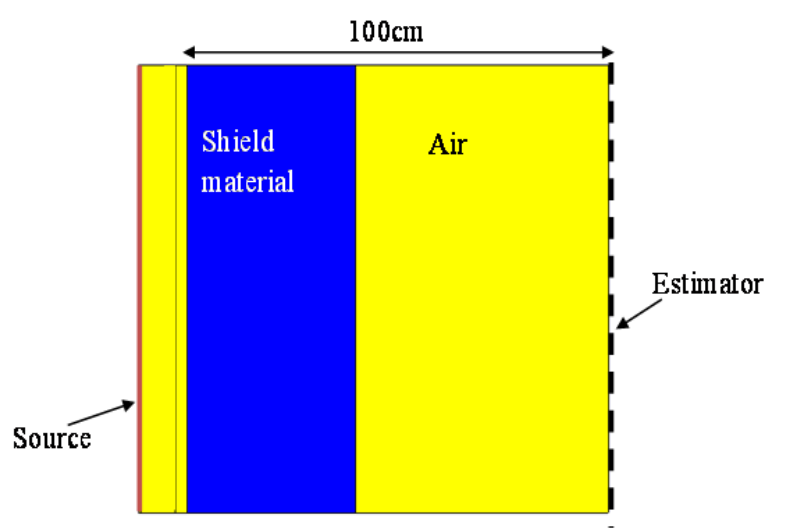

Figure 1. Calculation model.

The shielding performance of polyethylene that does not contain boron worsens at greater thicknesses. For thermal neutrons, the shielding performance of NSC is better than that of other materials. At $100 \mathrm{keV}$, its shielding performance is better than that of the other materials at thicknesses greater than $16 \mathrm{~cm}$. However, for DD neutrons, polyethylene outperforms the NSC. This is because polyethylene contains many hydrogen atoms.

\section{Application to TAIKAN}

The original shielding design for TAIKAN, which is shown in Figure 3, had a multilayer structure of BAR and OC. Figure 4 shows the optimized shielding design using NSC. This design was obtained by a parameter
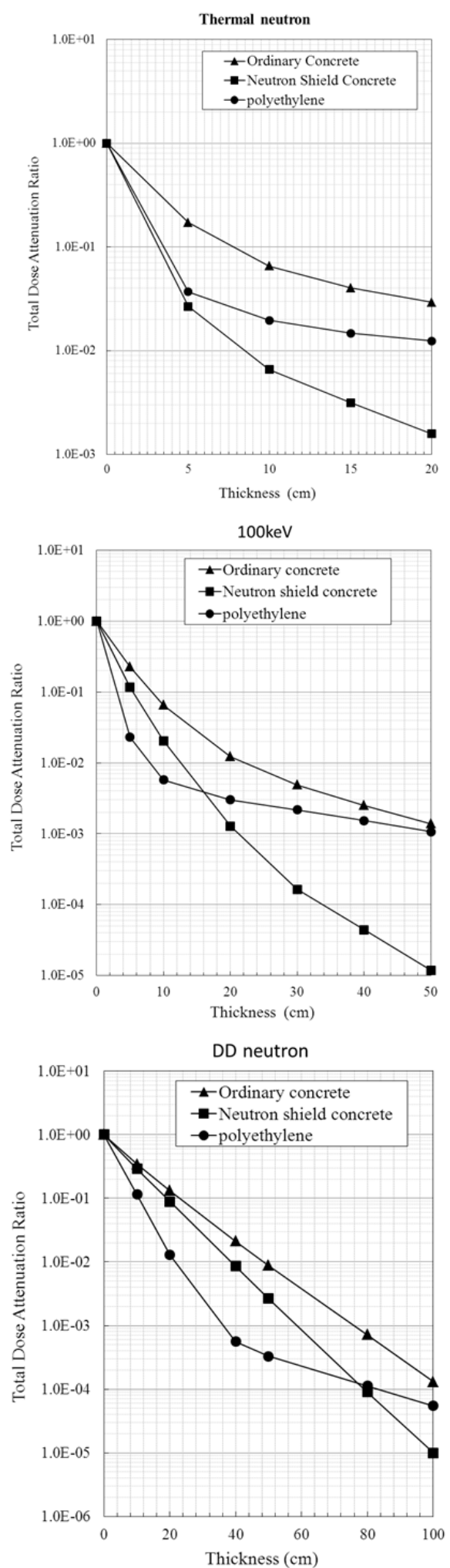

Figure 2. Basic shielding properties of NSC and other materials. 
survey using PHITS code $^{3)}$. PHITS code is used for radiation safety estimation as standard code at J-PARC. PHITS code and MCNP code use the same radiation transport theory for energies under $20 \mathrm{MeV}$.

Note that eponite in Figure 4 is a mixture of colemanite and epoxy resin ${ }^{4}$. The original design was used BAR, but in the optimized design, the BAR was removed. The change in the material's thickness when NSC was used is shown in Table 2.

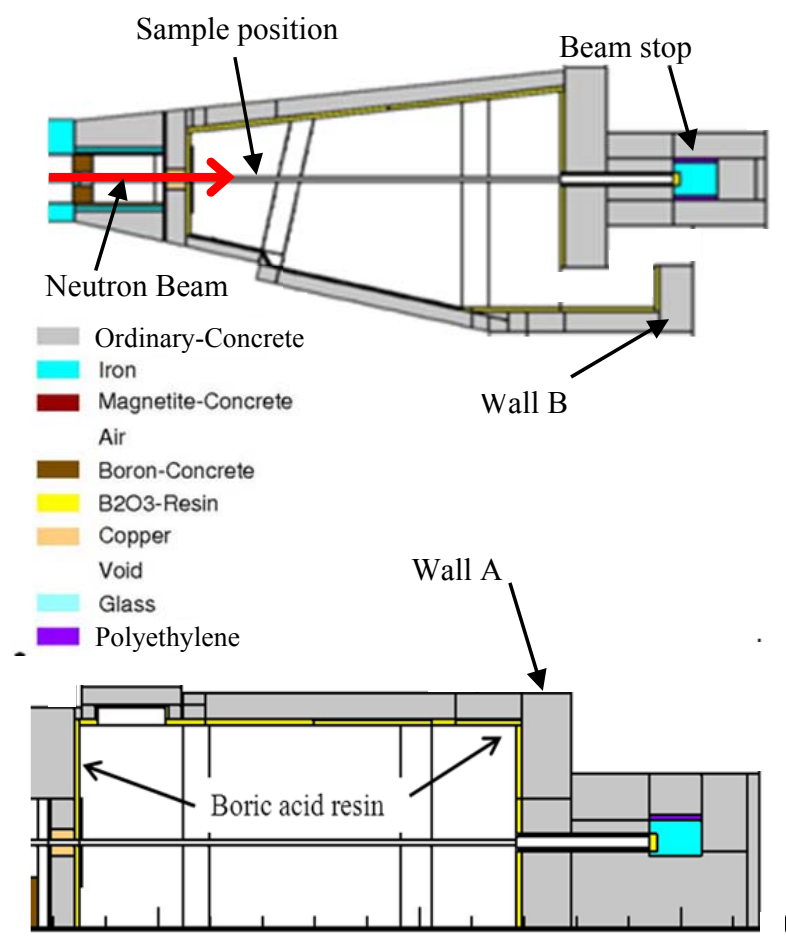

Figure 3. Original shield design of TAIKAN.

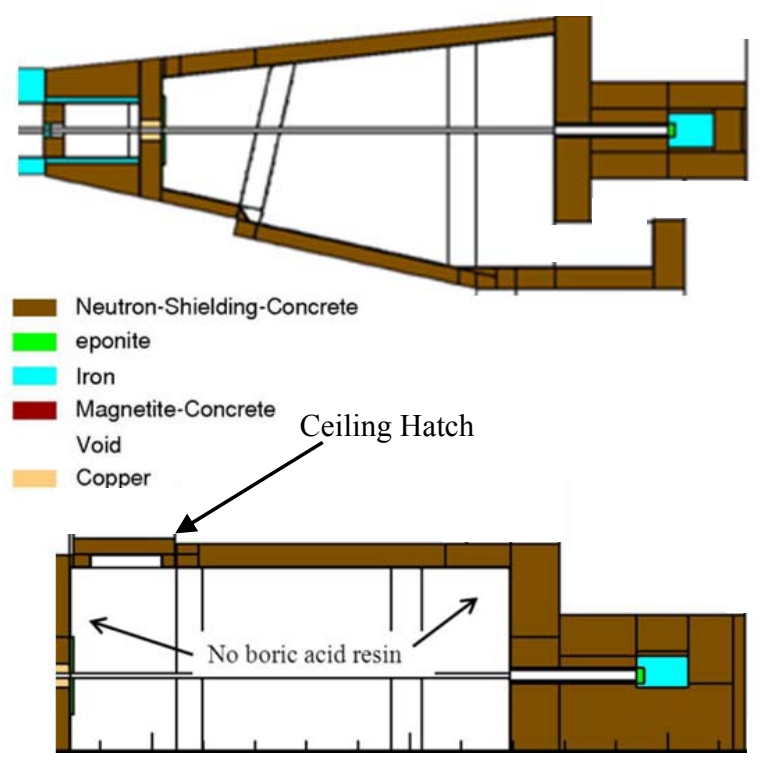

Figure 4. Optimized shield design of TAIKAN.
To confirm whether the shielding performance of the optimized design totally satisfied the dose criteria, a shielding calculation using the PHITS code was performed. The calculation model was the same as that shown in the drawings. An iron sample with dimensions $1 \mathrm{~mm} \times 30 \mathrm{~mm} \varphi$ was placed at the sample position.

Table 2. Thicknesses of material in the original and optimized designs.

\begin{tabular}{ccc}
\hline & Original & Optimum \\
\hline Ceiling & BAR $10 \mathrm{~cm}+$ OC $45 \mathrm{~cm}$ & NSC $43.5 \mathrm{~cm}$ \\
\hline Wall A & BAR $10 \mathrm{~cm}+$ OC $95 \mathrm{~cm}$ & NSC $77 \mathrm{~cm}$ \\
\hline Wall B & BAR $10 \mathrm{~cm}+$ OC $75 \mathrm{~cm}$ & NSC $66 \mathrm{~cm}$ \\
\hline $\begin{array}{c}\text { Behind the } \\
\text { beam stop }\end{array}$ & OC $110 \mathrm{~cm}$ & NSC $77 \mathrm{~cm}$ \\
\hline
\end{tabular}

Original design
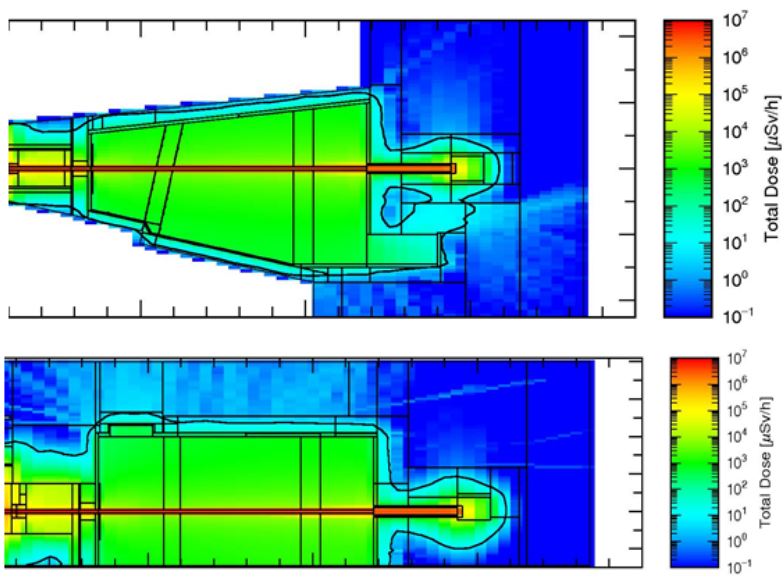

Optimized design

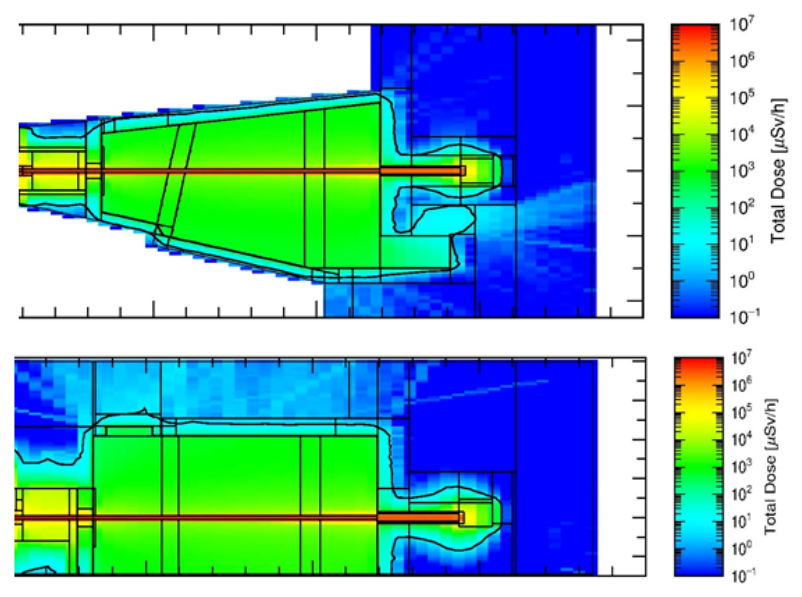

Figure 5. Dose distribution of TAIKAN.

The result of the calculation is shown in Figure 5. The counter line indicates the dose criteria for areas outside of the shielding room. The dose distributions of the original and optimized designs were almost the same. Further, the counter line does not extend beyond the shield room. 
Therefore, the calculation confirmed the radiation safety of the optimized design using NSC.

The averaged dose value in each design for the ceiling hatch and the area behind the beam stop made of iron are shown in Figure 6, respectively. Although the dose distribution in the ceiling hatch is almost the same for both designs, that behind the beam stop differs. The shielding performance of the optimized design is about twice as good as that of the original one.
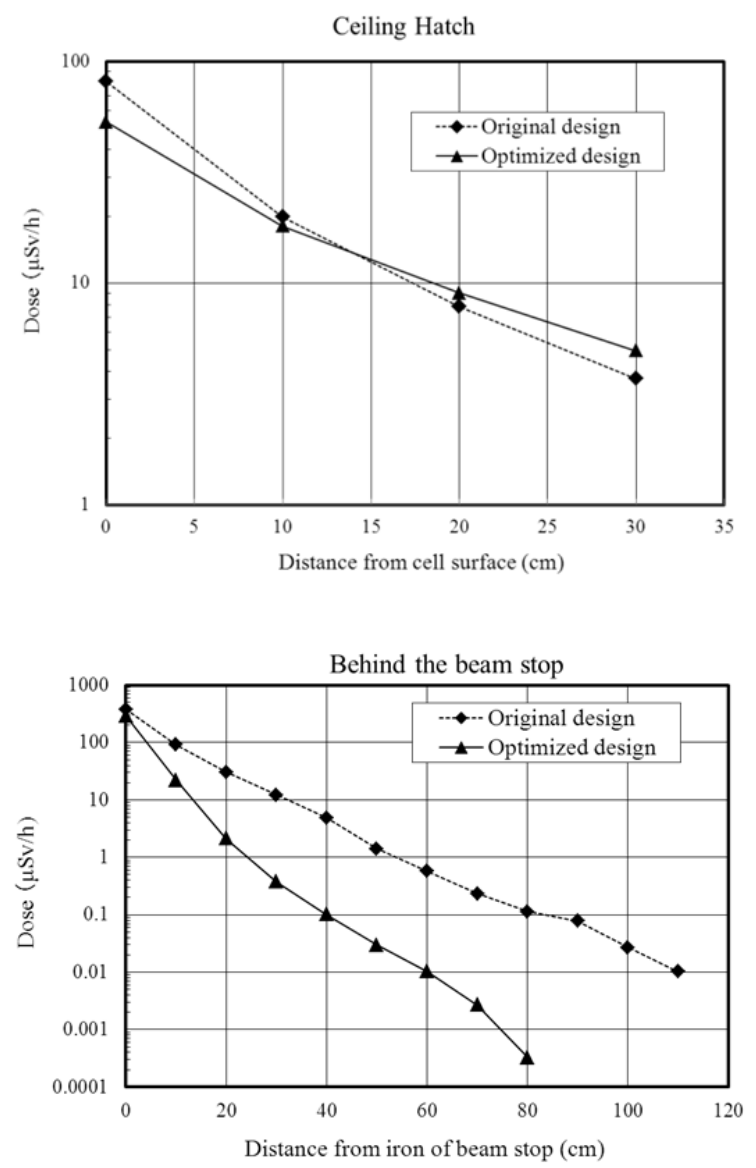

Figure 6. Dose distributions in the concrete.
This is because in the original design many low-energy neutrons remain behind the iron beam stop, which has poor shielding performance for low-energy neutrons. Because the NSC contains much boron, it captured low-energy neutrons.

Although TAIKAN uses neutrons ranging in energy from $10^{-3} \mathrm{eV}$ to $0.3 \mathrm{eV}$, the energy spectrum of the neutron source used in this calculation went up to 250 $\mathrm{MeV}$ by radiation safety regulation of J-PARC. Thus, high-energy neutrons exist in the ceiling. Therefore, the dose distribution in the ceiling is almost the same as that in $\mathrm{OC}$.

\section{Conclusion}

A NSC was applied to the TAIKAN neutron scattering instrument at J-PARC. By using NSC, the thickness of the shield could be reduced to about $70 \%$ of that of the original design, which used OC.

Construction work also became simpler because the BAR was removed. The resulting slimmer neutron shield structure could leave more space in the interior shielded areas.

\section{References}

[1] K. Okuno, M. Kawai and H. Yamada, Development of Novel Neutron Shielding Concrete, Nucl. Technol. 168 (2009), pp. 545-552.

[2] X-5 Monte Carlo Team, MCNP-A General Monte Carlo N-Particle Transport Code, Version 5, Los Alamos National Laboratory, (2003).

[3] K. Niita, N. Matsuda, Y. Iwamoto, H. Iwase, T. Sato, H. Nakashima, Y. Sakamoto and L. Sihver, PHITS: Particle and Heavy Ion Transport Code System, Version 2.23, JAEA-Data/Code 2010-022, Japan Atomic Energy Research Institute, (2010).

[4] K. Okuno, Neutron Shielding Material Based on Colemanite and Epoxy Resin, Radiat. Prot. Dosim. 115, 1-4 (2005), pp. 258-261. 